\title{
THE CORRELATION BETWEEN FOETAL MOVEMENTS COUNT AND FOETAL OUTCOME
}

\section{Dr. Mamta Gangwal}

Assistant Professor, Department of Obstetrics and Gynecology, RVRS Medical College, Bhilwara

Article Info: Received 21 November 2019; Accepted 15 December 2019

DOI: https://doi.org/10.32553/ijmbs.v3i12.807

Corresponding author: Dr. Mamta Gangwal

Conflict of interest: No conflict of interest.

\section{Abstract}

Background: A reduced fetal movement is a common indication for assessment of fetal well being. A reduced fetal movement is considered as high risk pregnancy because the fetus is at high risk of hypoxia and sudden demise.

Methods: Hospital based prospective study conducted at Department of Obstetrics and Gynecology, RVRS Medical College, Bhilwara. Total 130 pregnant women were included in this study.

Results: $10.77 \%$ patients didn't perceive fetal movements after admission. Out of 14 patients with absent DFMC, 6 babies (42.86\%) died and 8 babies (57.14\%) survived. The association betweenNon Stress Test and mode of delivery was found statistically significant. 83.33\%) were admitted in NICU. Out of 24 patients presenting with non reactive NST, 20.83\% (5) babies born with APGAR score more than 7 and $79.17 \%$ (19) babies had APGAR score 4-7.

Conclusion: The association between NST \& DFMC and fetal outcome was found statistically significant. Keywords: DFMC, NST, Fetal outcome, survived.

\section{Introduction}

Motherhood makes a woman complete and childbirth is the most beautiful gift, a woman is endowed with. As obstetricians, our ultimate goal remains to have a healthy mother and healthy child at the end of a normal uncomplicated pregnancy. Regular antenatal care throughout the pregnancy, tailored to a woman's need is required to ensure good outcome.

Fetuses with major malformations are generally more likely to demonstrate reduced fetal activity. However, normal or excessive fetal activity has been reported in anencephalic fetus. A reduced fetal movement is a common indication for assessment of fetal well being. A reduced fetal movement is considered as high risk pregnancy because the fetus is at high risk of hypoxia and sudden demise. A lack of vigorous motion may be related to abnormalities of the central nervous system, muscular dysfunction or skeletal abnormalities. Sedating drugs, which cross the placenta such as alcohol, methadone, benzodiazepines and other opioids can be associated with reduced fetal movements. ${ }^{1}$

Perinatal period is the most vulnerable period in the life of an individual and the rate of death during this period is higher than any other period of life. Pre term births, infections, hypertensive diseases and intrapartum asphyxia are cited as most important contributors for perinatal mortality. ${ }^{2}$ Almost $2 / 3$ rd of perinatal deaths occur due to obstetric factors, perinatal hypoxia and infections, which are preventable causes. To address this problem, various antenatal fetal surveillance methods have been devised in the past few decades and the search for best is still ongoing. Antepartum fetal testing is a compilation of methods devised to differentiate normal from compromised fetuses prior to onset of labor. The main techniques for fetal assessment are non-stress test (NST), contraction stress test (CST), Biophysical profile, fetal movements count, modified Biophysical Profile Score and Umbilical Artery Doppler Velocimetry. ${ }^{3}$ The NST and CST are two primary methods available for fetal surveillance but are poor predictors of an asphyxiated fetus.

Biophysical Profile is the combination of NST and dynamic real-time $B$ mode ultra-sonographic assessment of certain fetal parameters. It is a clinical tool that integrates level of dynamic biophysical activities into a usable standard. ${ }^{7}$ It includes both acute markers of fetal status and some chronic markers of fetal and intrauterine conditions. Biophysical profile predicts neonatal acidosis at delivery better than APGAR score and thus the risk of 
fetal death. In a compromised fetus, measures can be taken to intervene before progressive metabolic acidosis leads to fetal death. ${ }^{4}$

The purpose of this study was to evaluate reduced fetal movements as an effective predictor for the assessment of fetal condition and to improve fetal outcome by early detection of fetal hypoxia, at Department of Obstetrics and Gynecology, SMS Medical College, Jaipur (Rajasthan).

\section{Material and Methods}

Type of Study:

An observational study.

\section{DURATION OF STUDY:}

April 2017 onwards for a period of one year till desired sample size is reached for data collection and 2 months for data compilation and analysis.

\section{Inclusion Criteria}

- Age 18-35 yr.

- $\quad$ Singleton pregnancy of $>37$ weeks of gestation.

- Women with decreased fetal movements.

- Women giving written consent.

\section{Exclusion Criteria}

- Women with intrauterine fetal death.

- Women in labor.

\section{Statistical Analysis}

Continuous variables were summarised as Mean and Standard Deviation whereas nominal / categorical variables as proportion (\%).

Unpaired ' $\mathrm{t}$ ' test and parametric test were used for analysis of continuous variables while chi-square test / Fischer exact test and other non-parametric test was used for normal / categorical variables.

p-value $<0.05$ was taken as significant.

MEDCALC 16.4 version software was used for all statistical analysis.

\section{Observations and Results}

Out of 130 patients, $78.47 \%$ patients were in $26-30$ years age group followed by $16.92 \%$ patients were in 20-25 years age group and $4.63 \%$ patients were in more than 30 years age group. 56.15\% women were primigravida followed by $22.31 \%$ were second gravida and $13.84 \%$ patients were multigravida.

Table 1: Distribution according to perception of fetal movements by mother after admission

\begin{tabular}{lll}
\hline DFMC & No. of women & Percentage \\
\hline Present & 116 & 89.23 \\
\hline Absent & 14 & 10.77 \\
\hline Total & $\mathbf{1 3 0}$ & $\mathbf{1 0 0 . 0 0}$ \\
\hline
\end{tabular}

Table shows that $10.77 \%$ patients didn't perceive fetal movements after admission.

Table 2: Association of perception of daily fetal movements (DFMC) after admissionwith fetal outcome

\begin{tabular}{llll}
\hline \multirow{2}{*}{ DFMC } & \multicolumn{2}{l}{ fetal outcome } & Total \\
\cline { 2 - 3 } & Survive & Death & \\
\hline Present & $116(100.00 \%)$ & $0(0.00 \%)$ & $116(89.23 \%)$ \\
\hline Absent & $8(57.14 \%)$ & $6(42.86 \%)$ & $14(10.77 \%)$ \\
\hline Total & $124(95.38 \%)$ & $6(4.62 \%)$ & $130(100.00 \%)$ \\
\hline
\end{tabular}

Chi-square $=13.65 \mathrm{df}=1 \quad \mathrm{p}$-value $=0.004$

Out of 14 patients with absent DFMC, 6 babies (42.86\%) died and 8 babies (57.14\%) survived. The association betweenDFMC and fetal outcome was found statistically significant.

Table 3: Association between Non Stress Test and mode of delivery.

\begin{tabular}{llll}
\hline \multirow{2}{*}{ NST } & \multicolumn{2}{l}{ Type of delivery } & Total \\
\cline { 2 - 3 } & ND & LSCS & \\
\hline Reactive & $81(76.42 \%)$ & $25(23.58 \%)$ & $106(81.54 \%)$ \\
\hline Non reactive & $5(20.83 \%)$ & $19(79.17 \%)$ & $24(18.46 \%)$ \\
\hline Total & $\mathbf{8 6}$ & $\mathbf{4 4}$ & $\mathbf{1 3 0 ( 1 0 0 . 0 0 \% )}$ \\
& $\mathbf{( 6 6 . 1 5 \% )}$ & $\mathbf{( 3 3 . 8 5 \% )}$ & \\
\hline
\end{tabular}

Chi-square $=27.00 \mathrm{df}=1 \quad p$-value $=0.001$

Out of 24 patients having non reactive NST, 19 babies (79.17\%) were delivered by LSCS and 5 babies (20.83\%) were delivered by ND. The association betweenNon Stress Test and mode of delivery was found statistically significant.

Table 4: Association between Non Stress test and APGAR score at $5 \mathrm{~min}$

\begin{tabular}{lllll}
\hline NST & \multicolumn{2}{l}{ APGAR score } & Total \\
\cline { 2 - 5 } & $\mathbf{1 - 3}$ & $\mathbf{4 - 7}$ & $\mathbf{7 7}$ & \\
\hline Reactive & 0 & 24 & 82 & 106 \\
& $(00.00 \%)$ & $(25.47 \%)$ & $(74.52 \%)$ & $(81.54 \%)$ \\
\hline Non & 0 & 19 & 5 & 24 \\
reactive & $(0.00 \%)$ & $(79.17 \%)$ & $(20.83 \%)$ & $(18.46 \%)$ \\
\hline Total & $\mathbf{0}$ & $\mathbf{4 3}$ & $\mathbf{8 7}$ & $\mathbf{1 3 0}$ \\
& $(\mathbf{0 . 0 0 \% )}$ & $\mathbf{( 3 3 . 0 8 \% )}$ & $\mathbf{( 6 6 . 9 2 \% )}$ & $\mathbf{( 1 0 0 . 0 0 \% )}$ \\
\hline
\end{tabular}

Chi-square $=54.97 \mathrm{df}=2 \quad \mathrm{p}$-value $=0.001$

Out of 24 patients presenting with non reactive NST, 20.83\% (5) babies born with APGAR score more than 7 and $79.17 \%$ (19) babies had APGAR score 4-7.

The association between NST and APGAR score was found statistically significant. 
Table 5: Association between Non Stress Test and NICU admission

\begin{tabular}{llll}
\hline \multirow{2}{*}{ NST } & \multicolumn{2}{l}{ NICU admission } & Total \\
\cline { 2 - 3 } & Yes & No & \\
\hline Reactive & $20(18.77 \%)$ & $86(81.23 \%)$ & $106(81.54 \%)$ \\
\hline Non reactive & $20(83.33 \%)$ & $4(16.67 \%)$ & $24(18.46 \%)$ \\
\hline Total & $\mathbf{4 0}$ & $\mathbf{9 0}$ & $\mathbf{1 3 0 ( 1 0 0 . 0 0 \% )}$ \\
& $\mathbf{( 3 0 . 7 7 \% )}$ & $\mathbf{( 6 9 . 2 3 \% )}$ & \\
\hline
\end{tabular}

Chi-square $=43.38 \mathrm{df}=1 \quad p$-value $=0.001$

Out of 24 cases, 20 babies (83.33\%) were admitted in NICU. The association between Non Stress Test and NICU admission was found statistically significant.

\section{Discussion}

The present study was undertaken to correlate decrease fetal movements with ultrasonography findings and fetal outcome in Department of Obstetrics and Gynaecology, SMS Medical College, Jaipur. This study was conducted on total 130 women.

In our study out of 130 women, $78.47 \%$ women were in $26-30$ years age group followed by $16.92 \%$ in $20-25$ years age group and $4.63 \%$ in more than 30 years age group. Mean age was 26.5 years. In a study conducted by Syeda. R.M et $\mathrm{al}^{4}$ on 50 women presenting with reduced fetal movements, $90 \%$ of the women were between 21-30 years.

In our study $72.30 \%$ women were in $26-30$ years age group because, $26-30$ years is the common child bearing age.

Maternal perception of fetal movement is an inexpensive, noninvasive method of assessing fetal well-being. Monitoring fetal movement serves as an indirect measure of central nervous system integrity and function. Short-term observations of the fetus are best performed using real-time ultrasound imaging or Doppler ultrasound ${ }^{5}$. For home monitoring daily fetal kick count may be required. Advocating the use of DFMC chart requires counseling for awareness. Kick count or mild flicker can be explained along with variation due to muscle spasm in winter and liquor quantity.

A healthy fetus should move approximately three to five times within one hour. An alternative method is the Cardiff Count-to-Ten chart, whereby the patient records fetal movements during the course of usual daily activity. A period of 12 hours without at least 10 perceived movements is considered a warning signal ${ }^{6}$. If the test result is not reassuring, the patient should be evaluated with NST and USG ${ }^{5}$.

Out of 14women, who persistently complained of DFM despite explaining DFMC, 6 had poor fetal outcome. The association between DFMC and fetal outcome was found statistically significant.

It is clear that complaints of decreased fetal movement are significant and warrant further evaluation ${ }^{6}$. The Society of Obstetrician and Gynecologists of Canada has recommended that DFMC could be used in cases identified to be at risk for fetal asphyxia ${ }^{7}$.

Out of 24 women who presented with non reactive NST, we found that $20.83 \%$ neonates had APGAR score at more than 7 at 5 minutes and $79.17 \%$ babies had APGAR score 4-7.The association between NST and APGAR was found statistically significant. Kikwai Willey Kibet et $\mathrm{al}^{8}$ also observed significant association between NST and APGAR score.

\section{Conclusion}

The association between NST \& DFMC and fetal outcome was found statistically significant.

\section{Bibliography}

1. Vintzileos AM, Campbell WA, Rodis JF. Foetal biophysical profile scoring: current status. Clin Perinatol. 1998;16(3):661-89.

2. Filho HA, Junior AE, Nardozza LM, Costa LL, Moron AF, Mattar R. Ultrasound assessement of the fetal biophysical profile: what does an radiologist need to know? Eur J Radiol. 2008;66(1):122-6.

3. Lalor JG, Fawole B, Alfirevic Z, Devane D. Biophysical profile for fetal assessment in high risk pregnancies. Cochrane Database Syst Rev. 2008;23:CD000038.

4. Syeda. R.M, Shakuntala. P.N, Rao SR et. al. Fetal outcome in pregnant women with reduced fetal movements. Int J Health Sci Res. 2013;3(7):18-28.

5. Christensen FC, Rayburn WF. Fetal movement counts. Obstet Gynecol Clin North Am. 1999;26:607621.

6. Sergent F, Lefevre A, Verspyck E, Marpeau L. Decreased fetal movements in the third trimester: what to do? Gynecol Obstet Fertil. 2005;33:861-869.

7. Davies Gregory AL. Antenatal fetal assessment. J Soc Obstet Gynaecol Can. 2000;22:456-462.

8. Kikwai Willey Kibet. Fetal Outcomes Among Pregnant Women Presenting With Reduced Fetal Movements At Kenyatta National Hospital: A Cross Sectional Study 